\title{
Case Report \\ Ocular Findings in the 16p11.2 Microdeletion Syndrome: A Case Report and Literature Review
}

\author{
Cybil S. Stingl $\mathbb{D},{ }^{1}$ Colleen Jackson-Cook $\mathbb{D},{ }^{2,3}$ and Natario L. Couser $\mathbb{D}^{2,4,5}$ \\ ${ }^{1}$ Virginia Commonwealth University School of Medicine, Richmond, VA, USA \\ ${ }^{2}$ Department of Human and Molecular Genetics, Virginia Commonwealth University School of Medicine, Richmond, VA, USA \\ ${ }^{3}$ Department of Pathology, Virginia Commonwealth University School of Medicine, Richmond, VA, USA \\ ${ }^{4}$ Department of Ophthalmology, Virginia Commonwealth University School of Medicine, Richmond, VA, USA \\ ${ }^{5}$ Department of Pediatrics, Virginia Commonwealth University School of Medicine, Richmond, VA, USA \\ Correspondence should be addressed to Cybil S. Stingl; stinglca@mymail.vcu.edu
}

Received 24 December 2019; Revised 3 March 2020; Accepted 11 March 2020; Published 20 April 2020

Academic Editor: John W. Berkenbosch

Copyright ( $) 2020$ Cybil S. Stingl et al. This is an open access article distributed under the Creative Commons Attribution License, which permits unrestricted use, distribution, and reproduction in any medium, provided the original work is properly cited.

\begin{abstract}
The recurrent 16p11.2 microdeletion is characterized by developmental delays and a wide spectrum of congenital anomalies. It has been well reported that individuals with this $\sim 593-\mathrm{kb}$ interstitial deletion have an increased susceptibility toward the autism spectrum disorder (ASD). Abnormalities of the eye and ocular adnexa are also commonly associated findings seen in individuals with the 16p11.2 microdeletion syndrome, although these ophthalmic manifestations have not been well characterized. We conducted an extensive literature review to highlight the eye features in patients with the 16p11.2 microdeletion syndrome and describe a 5-year-old boy with the syndrome. The boy initially presented with intellectual disability, speech delay, and defiant behavior; diagnoses of attention deficit hyperactivity disorder (ADHD) and oppositional defiant disorder (ODD) were established. $\mathrm{He}$ had a Chiari malformation type 1. His ophthalmic features included strabismus, hyperopia, and ptosis, and a posterior embryotoxon was present bilaterally. From a systematic review of prior reported cases, the most common eye and ocular adnexa findings observed were downslanting palpebral fissures, deep-set eyes, ptosis, and hypertelorism.
\end{abstract}

\section{Introduction}

The 16p11.2 microdeletion syndrome (OMIM \# 611913) is a rare congenital condition with an estimated frequency of 3 in 10,000 in the general Icelandic public [1]. The microdeletion is also present in 1 in 100 persons with autism and 1 in 1,000 persons with a language or psychiatric disorder, most notably speech delay and schizophrenia [1-3]. The syndrome most classically involves a heterozygous microdeletion of about $593-\mathrm{kb}$ from band $16 \mathrm{p} 11.2$, which is localized to the short arm $(p)$ of chromosome 16 [4]. A majority of cases reported are de novo, but the deletion is inherited in an autosomal dominant fashion from a parent $20 \%$ of the time [4]. An equal sex ratio has been reported [4]. The 16p11.2 microdeletion syndrome is characterized by the presence of developmental delays related to expressive language skills, autism spectrum disorder (ASD), diminished cognitive function, macrocephaly, hypotonia, Chiari malformation, learning disabilities, and high risk of encopresis and obesity $[3,4]$. Seizures are reported in approximately $20 \%$ of individuals affected [4]. Reported cases of 16p11.2 microdeletion have included variable ocular findings [5-25]. We conducted an extensive literature review to summarize the eye features in patients with the microdeletion syndrome reported, to date, and describe a new case of a 5-year-old boy with the 16p11.2 microdeletion syndrome.

\section{Case Report}

Our patient, now a 5 -year-old boy, was born at $365 / 7$ weeks via vaginal delivery as the second child to a mother with a pregnancy complicated by subchorionic hematoma and bleeding at 17 weeks; birth weight was $6 \mathrm{lbs} 13 \mathrm{oz}$. Tobacco use ( $1 / 2$ pack per day) was present for the first 3 months of 


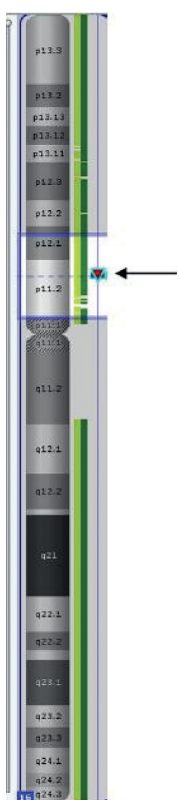

(a)

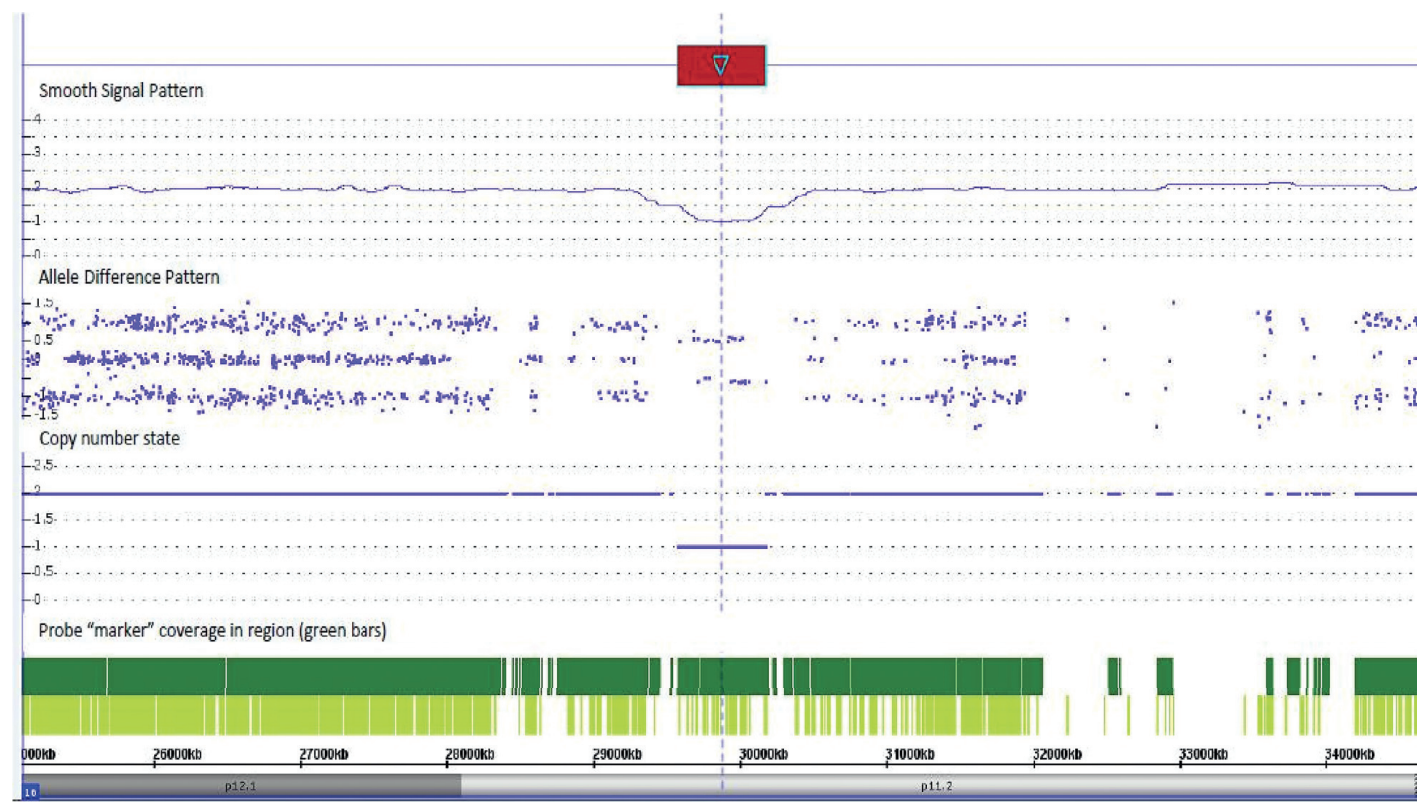

Partial ideogram for chromosome 16 (gray bands) showing nucleotide location (GRCh37)

(b)

Figure 1: Deletion of 16p11.2 noted using microarray technology. (a) An ideogram of chromosome 16 shows the location of the deletion that is present in this patient in the context of the entire chromosome 16 (arrows). (b) The area highlighted (lighter colored region) in portion (a) of this figure is shown in an expanded view in this image. The deletion in this patient (highlighted by the red arrow; top row) is shown via smooth signal and allele difference patterns, as well as copy number state values. This deletion is localized to band $16 \mathrm{p} 11.2$ (nucleotides 29567295_30177999) [GRCh37].

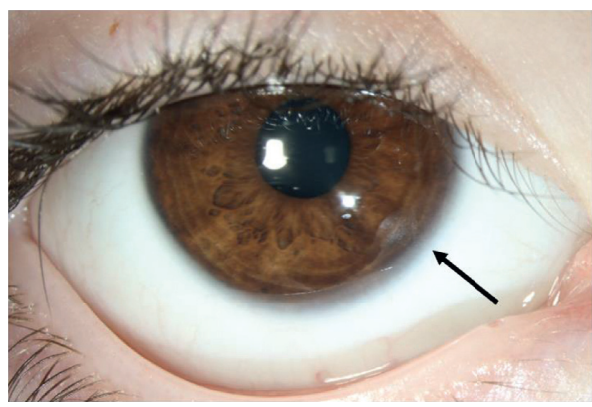

(a)

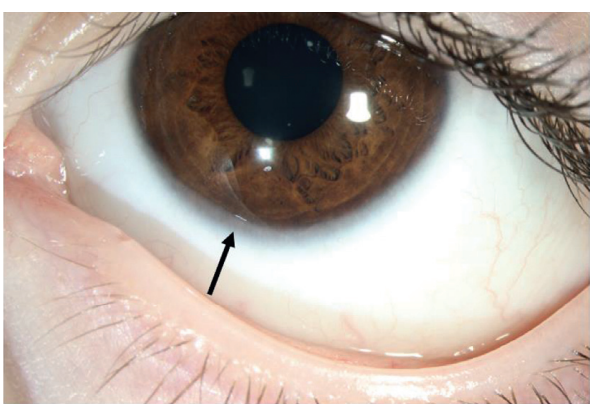

(b)

Figure 2: External photograph of the (a) right and (b) left eye showing the posterior embryotoxon (arrows).

pregnancy. Paternal family history was notable for the presence of multiple personality disorder, depression, and schizophrenia.

Additional medical problems of the patient included significant speech and language delay, hypotonia with gait abnormality, encopresis, incontinence, hyperphagia with elevated BMI (85th percentile), attention deficit hyperactivity disorder (ADHD), oppositional defiant disorder (ODD), and Chiari malformation type 1.

Chromosomal microarray revealed a pathogenic microdeletion at 16p11.2(29567295_30177999)x1 (Figure 1). Parental testing revealed the mother was negative for the 16p11.2 microdeletion. The father was deceased and thus was not available for genetic testing.
At his most recent exam at 5 years and 3 months of age, ocular abnormalities included strabismus (intermittent exodeviation), bilateral mild hyperopia, ptosis of the left eyelid, and posterior embryotoxon present bilaterally (Figure 2).

\section{Methods}

We performed a systematic review of the literature to summarize the reported ocular and ophthalmic features in individuals with confirmed $16 \mathrm{p} 11.2$ microdeletions. A PubMed search of "16p11.2 Microdeletion Syndrome" led to a total of 44 articles; these articles, along with their references, were reviewed in search of ocular findings. 
TABLe 1: Ocular findings by patient.

\begin{tabular}{|c|c|c|c|}
\hline Patient & Year & Reference & Ophthalmic findings \\
\hline 1 & 2019 & $\begin{array}{l}\text { Stingl et al. (this } \\
\text { report) }\end{array}$ & $\begin{array}{l}\text { Intermittent exodeviation, mild hyperopia bilaterally, ptosis of the left eyelid, and a posterior } \\
\text { embryotoxon bilaterally }\end{array}$ \\
\hline 2 & 2018 & Dell'Edera et al. [8] & Hypertelorism (interpupillary distance of $2.9 \mathrm{~cm}$ ), mildly downslanting palpebral fissures \\
\hline 3 & 2018 & Gatti et al. [22] & $\begin{array}{c}\text { Downslanting palpebral fissures, slight eversion of the lateral third of the lower eyelid, long } \\
\text { eyelashes }\end{array}$ \\
\hline 4 & 2015 & $\begin{array}{l}\text { Moreno-Igoa et al. } \\
{[13]}\end{array}$ & $\begin{array}{c}\text { Short and upslanting palpebral fissures, hypertelorism, epicanthal folds, ptosis of the eyelids, iris } \\
\text { heterochromia }\end{array}$ \\
\hline 5 & 2014 & D’Angelo et al. [7] & Deep-set eyes \\
\hline 6 & 2014 & $\begin{array}{l}\text { Pebrel-Richard et al. } \\
{[14]}\end{array}$ & Acute visual impairment appeared with retinitis pigmentosa and progressive visual loss \\
\hline 7 & 2014 & Gerundino et al. [21] & Downslanting palpebral fissures with deep-set eyes \\
\hline 8 & 2012 & Kino et al. [11] & Hypertelorism \\
\hline 9 & 2012 & Tabet et al. [18] & Deep-set eyes, thick supraorbital ridge \\
\hline 10 & & & Patient 1: sagging lateral upper eyelids \\
\hline 11 & 2011 & Barge-schaapveld et & Patient 4: Full lateral part of the upper eyelids \\
\hline 12 & 2011 & al. $[6]$ & $\begin{array}{c}\text { Patient 3: right-sided convergent strabismus, hypotelorism, narrow palpebral fissures, full lateral } \\
\text { part of the upper eyelids, relatively thin eyebrows with lateral notches }\end{array}$ \\
\hline 13 & & & Prominent eyes \\
\hline 14 & 2011 & Schaat et al. [15] & Mild horizontal nystagmus on extreme lateral gaze \\
\hline 15 & 2010 & Bardakjian et al. [5] & $\begin{array}{c}\text { Left microphthalmia, persistent hyperplastic primary vitreous and posterior coloboma, right } \\
\text { posterior pole coloboma }\end{array}$ \\
\hline 16 & & & Mild hypertelorism \\
\hline 17 & & & Downslanting palpebral fissures \\
\hline 18 & & & Deep-set eyes \\
\hline 19 & 2010 & Shinawi et al. [9] & Hyper \\
\hline 20 & & & "Almond shaped" eyes \\
\hline 21 & & & Hypertelorism \\
\hline 22 & & & Proband 2, 13yo boy: long, narrow palpebral fissures \\
\hline 23 & 2010 & Fernandez et al. [17] & proband3c (mother): deep-set \\
\hline 24 & & & Proband 3, 5 yo male: hypertelorism (inner canthal distance $3.4 \mathrm{~cm},>+2 \mathrm{SD}$ ) \\
\hline 25 & 2010 & Sampson et al. [20] & Retinal dystrophy, retinitis pigmentosa \\
\hline 26 & 2009 & Shimojima et al. [16] & Bilateral ptosis \\
\hline 27 & 2009 & Hemple et al. [23] & Deep-set ey \\
\hline 28 & & & Short pa \\
\hline 29 & & & Short and down-slanted palpebral fissures \\
\hline 30 & & & Hypertelorism, bilateral epicanthic folds, short palpebral fissures, mild ptosis \\
\hline 31 & & & Prominent infraorbital skin creases \\
\hline 32 & 2009 & Bijlsma et al. [24] & Slightly deep-set eyes \\
\hline 33 & & & Mild ptosis \\
\hline 34 & & & Blepharophimosis, ptosis, epicanthus inversus, telecanthus \\
\hline 35 & & & Downslanting and narrow palpebral fissures \\
\hline 36 & & & Downslanting and narrow palpebral fissures \\
\hline 37 & 2008 & Kumar et al. [12] & Downslanting palpebral fissures \\
\hline 38 & & & $\begin{array}{c}\text { Downslanting palpebral fissures; bilateral epicanthal folds; deep-set eyes; absent tear ducts; } \\
\text { strabismus }\end{array}$ \\
\hline 39 & & & Short and downslanting palpebral fissures; relative hypotelorism (3rd-10th percentile) \\
\hline 40 & 2007 & Ballif et al. [19] & Downslanting palpebral fissures; left epicanthal fold; hypotelorism \\
\hline 41 & & & Downslanting palpebral fissures; mild epicanthal folds; deep-set eyes \\
\hline 42 & & & $\begin{array}{c}\text { Narrow and slightly short palpebral fissures; relative hypertelorism (0 to }+1 \mathrm{SD}) \text {; ptosis (right eye); } \\
\text { strabismus (left eye); hyperopia }\end{array}$ \\
\hline 43 & 2002 & Hernando et al. [10] & Blepharophimosis, coloboma and unilateral chorioretinitis (right eye) \\
\hline
\end{tabular}

Additionally, all 27 references used for the OMIM 16p11.2 microdeletion syndrome entry (MIM \# 611913) were reviewed, along with their references. There were reports on an estimated 140 patients with the $16 \mathrm{p} 11.2$ microdeletion syndrome; 42 patient reports included descriptions of associated eye features (Table 1). The LeBlanc and Nelson study with 19 genetically confirmed 16p11.2 microdeletion patients was excluded from this analysis due to a lack of eye and ocular adnexa descriptions for their probands [25]. After including our patient, we calculated the frequency and prevalence of each ocular finding from the total number of cases with a confirmed deletion and reported eye findings (Table 2). No articles were excluded based on year published, and one article was excluded based on language. 
TABle 2: Frequency of ocular findings.

\begin{tabular}{lcc}
\hline Ocular findings & Number $(n)$ & Frequency (\%) \\
\hline Abnormal palpebral fissures & 18 & 41.9 \\
${ }^{*}$ Downslanting & 12 & 66.7 \\
${ }^{*}$ Upslanting & 1 & 5.6 \\
${ }^{*}$ Narrow & 5 & 27.8 \\
${ }^{*}$ Short & 6 & 33.3 \\
${ }^{*}$ Long & 1 & 5.6 \\
Deep-set eyes & 9 & 20.9 \\
Ptosis & 8 & 18.6 \\
Hypertelorism & 8 & 18.6 \\
Epicanthal folds & 4 & 9.3 \\
Strabismus & 4 & 9.3 \\
Retinitis pigmentosa & 2 & 4.7 \\
Coloboma & 2 & 4.7 \\
Blepharophimosis & 2 & 4.7 \\
Hypotelorism & 2 & 4.7 \\
Hyperopia & 2 & 4.7 \\
Full lateral part of the upper eyelids & 2 & 4.7 \\
Iris heterochromia & 1 & 2.3 \\
Thick supraorbital ridge & 1 & 2.3 \\
Microphthalmia & 1 & 2.3 \\
Chorioretinitis & 1 & 2.3 \\
Prominent eyes & 1 & 2.3 \\
Horizontal nystagmus & 1 & 2.3 \\
Retinal dystrophy & 1 & 2.3 \\
Absent tear ducts & 1 & 2.3 \\
Eyelid eversion & 1 & 2.3 \\
Long eyelashes & 1 & 2.3 \\
Sagging lateral upper eyelids & 1 & 2.3 \\
Prominent infraorbital skin creases & 1 & 2.3 \\
Epicanthus inversus & 1 & 2.3 \\
Telecanthus & 1 & 2.3 \\
Posterior embryotoxon & 1 & 2.3 \\
* & & \\
\hline
\end{tabular}

${ }^{*}$ Frequency within the subset of patients presenting with abnormal palpebral fissures.

\section{Discussion}

A systematic literature review revealed a total of 42 patients with confirmed 16p11.2 microdeletion and reported ophthalmic findings (Table 1) [5-25]. After including our patient, we calculated the frequency and prevalence of each ocular finding out the 43 patients with a confirmed deletion and reported eye findings (Table 2).

The 16p11.2 microdeletion syndrome was first reported in association with multiple congenital anomalies in 2002 in a boy who died at 5 months of age due to cardiac failure. The ocular findings of blepharophimosis, coloboma, and unilateral chorioretinitis were all reported in this initial case [10]. In 2007, data regarding facial dysmorphism in 16p11.2 microdeletion syndrome were published by Ballif et al. The dysmorphic features of 5 patients with confirmed microdeletions of $16 \mathrm{p} 11.2$ included the ocular findings of palpebral fissures, epicanthal folds, deep-set eyes, absent tear ducts, strabismus, hypoand hypertelorism, and hyperopia [19]. In 2008, additional information regarding facial dysmorphism in a boy with 16p11.2 microdeletion was published by Kumar et al. This report consisted of downslanting palpebral fissures, prominent ears, and broad nasal root [12]. In 2009,
Shimojima et al. reported the case of a 3-year-old boy with a confirmed 16p11.2 microdeletion. This boy was described with mildly dysmorphic features, bilateral ptosis, developmental delay, speech delay, hemivertebrae, early onset obesity, and dilation of the lateral ventricles on brain MRI [16]. Since then, there have been reports on over 130 patients with documented $16 \mathrm{p} 11.2$ microdeletions; the majority of these reports lack ophthalmic descriptions. It is possible these patients without reported eye manifestations did not have abnormal eye or ocular adnexa features, although we suspect the omission of reported eye features was more frequently related to the particular concentration of topics within each individual report. For example, an article titled "The copy number variation landscape of congenital anomalies of the kidney and urinary tract" by Miguel Verbitsky et al. describes extrarenal malformations in a variety of patients with copy number variants (CNV), including 9 patients with confirmed 16p11.2 microdeletions; ophthalmic manifestations were not featured [26].

Of the reports that included ophthalmic descriptions, the most common eye feature reported was abnormal palpebral fissures $(n=18$, freq $=41.9 \%)$. Downslanting was the most common description of palpebral fissures $(n=12$, freq $=66.7 \%)$, along with short $(n=6$, freq $=33.3 \%)$ and narrow $(n=5$, freq $=27.8 \%)$. Less commonly, there was one report of upslanting $(n=1$, freq $=5.6 \%)$ and one report of long $(n=1$, freq $=5.6 \%)$ palpebral fissures. The next most common ocular findings following abnormal palpebral fissures was deep-set eyes $(n=9$, freq $=20.9 \%)$. This was followed by both ptosis and hypertelorism $(n=8$, freq $=18.6 \%)$ (Table 2$)$. Epicanthal folds and strabismus $(n=4$, freq $=9.3 \%)$ were also common ocular findings. Infrequent reportings were notable for retinitis pigmentosa, coloboma, blepharophimosis, hypotelorism, hyperopia, and full lateral part of the upper eyelids $(n=2$, freq $=4.7 \%)$. Isolated ophthalmic features included iris heterochromia, thick supraorbital ridge, microphthalmia, chorioretinitis, prominent eyes, horizontal nystagmus, retinal dystrophy, absent tear ducts, eyelid eversion, long eyelashes, sagging lateral upper eyelids, prominent infraorbital creases, epicanthus inversus, and telecanthus $(n=1$, freq $=2.3 \%)$.

In summary, this report and literature review of the 16p11.2 microdeletion syndrome contributes to our understanding of the relationship of the $16 \mathrm{p} 11.2$ microdeletion and ocular abnormalities and provides incentive to further investigate the phenotype. A limitation of our study was the inability to directly compare the frequency of these ocular findings to their incidence in the general public. Further studies with a larger sample size could be beneficial to distinguish whether many of these features are indeed a true correlation with this microdeletion syndrome. We also recommend further investigation on the role of $16 \mathrm{p} 11.2$ microdeletion in eye development to help elucidate the mechanisms underlying ophthalmologic and adnexa abnormalities seen in the syndrome. 


\section{Conflicts of Interest}

N. L. Couser, MD, MS: (1) Retrophin, Inc.: principal investigator at the Virginia Commonwealth University site, (2) Elsevier: book author.

\section{References}

[1] L. A. Weiss, Y. Shen, J. M. Korn et al., "Association between microdeletion and microduplication at 16p11.2 and autism," New England Journal of Medicine, vol. 358, no. 7, pp. 667-675, 2008.

[2] D. T. Miller, M. P. Adam, S. Aradhya et al., "Consensus statement: chromosomal microarray is a first-tier clinical diagnostic test for individuals with developmental disabilities or congenital anomalies," The American Journal of Human Genetics, vol. 86, no. 5, pp. 749-764, 2010.

[3] Miller, D., PhD M. D., \& Hultén, M., 2013, 16p11.2 Microdeletions. Unique: Understanding Chromosome Disorders UNIQUE-Rare Chromosome Disorder Support Group, Oxted, UK, http://rarechromo.org.

[4] D. T. Miller, W. Chung, R. Nasir et al., "16p11.2 Recurrent Microdeletion," in GeneReviews ${ }^{\circledR}$ [Internet], M. P. Adam, H. H. Ardinger, R. A. Pagon et al., Eds., University of Washington, Seattle, Washington, DA, USA, 2019, https:// www.ncbi.nlm.nih.gov/books/NBK11167/.

[5] T. M. Bardakjian, S. Kwok, A. M. Slavotinek, and A. S. Schneider, "Clinical report of microphthalmia and optic nerve coloboma associated with a de novo microdeletion of chromosome 16p11.2," American Journal of Medical Genetics Part A, vol. 152A, no. 12, pp. 3120-3123, 2010.

[6] D. Q. C. M. Barge-schaapveld, S. M. Maas, A. Polstra, L. C. Knegt, and R. C. M. Hennekam, "The atypical 16p11.2 deletion: a not so atypical microdeletion syndrome?" American Journal of Medical Genetics Part A, vol. 155, no. 5, pp. 1066-1072, 2011.

[7] C. S. D’angelo, M. C. Varela, D. castro CIe et al., "Investigation of selected genomic deletions and duplications in a cohort of 338 patients presenting with syndromic obesity by multiplex ligation-dependent probe amplification using synthetic probes," Molecular cytogenetics, vol. 7, no. 1, p. 75, 2014.

[8] D. Dell'edera, C. Dilucca, A. Allegretti et al., "16p11.2 microdeletion syndrome: a case report," Journal of Medical Case Reports, vol. 12, no. 12, p. 90, 2018.

[9] B. A. Fernandez, W. Roberts, B. Chung et al., "Phenotypic spectrum associated with de novo and inherited deletions and duplications at $16 \mathrm{p} 11.2$ in individuals ascertained for diagnosis of autism spectrum disorder," Journal of Medical Genetics, vol. 47, no. 3, pp. 195-203, 2010.

[10] C. Hernando, A. Plaja, M. A. Rigola et al., "Comparative genomic hybridisation shows a partial de novo deletion 16 p11.2 in a neonate with multiple congenital malformations," Journal of Medical Genetics, vol. 39, no. 5, p. E24, 2002.

[11] T. Kino, M. G. Pavlatou, A. G. Moraitis, R. L. Nemery, M. Raygada, and C. A. Stratakis, "ZNF764 haploinsufficiency may explain partial glucocorticoid, androgen, and thyroid hormone resistance associated with $16 \mathrm{p} 11.2$ microdeletion," The Journal of Clinical Endocrinology \& Metabolism, vol. 97, no. 8, pp. E1557-E1566, 2012.

[12] R. A. Kumar, S. Karamohamed, J. Sudi et al., "Recurrent 16p11.2 microdeletions in autism," Human Molecular Genetics, vol. 17, no. 17, pp. 628-638, 2008.

[13] M. Moreno-igoa, B. Hernández-charro, A. Bengoa-alonso et al., "KANSL1 gene disruption associated with the full clinical spectrum of 17q21.31 microdeletion syndrome," BMC Medical Genetics, vol. 16, p. 68, 2015.

[14] C. Pebrel-richard, A. Debost-legrand, E. Eymard-pierre et al., "An unusual clinical severity of 16p11.2 deletion syndrome caused by unmasked recessive mutation of CLN3," European Journal of Human Genetics, vol. 22, no. 3, pp. 369-373, 2014.

[15] C. P. Schaaf, R. P. Goin-kochel, K. P. Nowell et al., "Expanding the clinical spectrum of the $16 \mathrm{p} 11.2$ chromosomal rearrangements: three patients with syringomyelia," European Journal of Human Genetics, vol. 19, no. 2, pp. 152-156, 2011.

[16] K. Shimojima, T. Inoue, Y. Fujii, K. Ohno, and T. Yamamoto, "A familial 593-kb microdeletion of 16p11.2 associated with mental retardation and hemivertebrae," European Journal of Medical Genetics, vol. 52, no. 6, pp. 433-435, 2009.

[17] M. Shinawi, P. Liu, S. H. L. Kang et al., "Recurrent reciprocal 16 p11.2 rearrangements associated with global developmental delay, behavioural problems, dysmorphism, epilepsy, and abnormal head size," Journal of Medical Genetics, vol. 47, no. 5 , pp. $332-341,2010$.

[18] A.-C. Tabet, M. Pilorge, R. Delorme et al., "Autism multiplex family with $16 \mathrm{p} 11.2 \mathrm{p} 12.2$ microduplication syndrome in monozygotic twins and distal 16p11.2 deletion in their brother," European Journal of Human Genetics, vol. 20, no. 5, pp. 540-546, 2012.

[19] B. C. Ballif, S. A. Hornor, E. Jenkins et al., "Discovery of a previously unrecognized microdeletion syndrome of 16p11.2p12.2," Nature Genetics, vol. 39, no. 9, pp. 1071-1073, 2007.

[20] M. G. Sampson, C. R. Coughlin, P. Kaplan et al., "Evidence for a recurrent microdeletion at chromosome 16p11.2 associated with congenital anomalies of the kidney and urinary tract (CAKUT) and Hirschsprung disease," American Journal of Medical Genetics Part A, vol. 152A, no. 10, pp. 2618-2622, 2010.

[21] F. Gerundino, G. Marseglia, C. Pescucci et al., "16p11. 2 de novo microdeletion encompassing SRCAP gene in a patient with speech impairment, global developmental delay and behavioural problems," European Journal of Medical Genetics, vol. 57, no. 11-12, pp. 649-653, 2014.

[22] M. Gatti, G. Tolva, S. Bergamaschi et al., "Mayer-RokitanskyKüster-Hauser syndrome and $16 \mathrm{p} 11.2$ recurrent microdeletion: a case report and review of the literature," Journal of Pediatric and Adolescent Gynecology, vol. 31, no. 5, pp. 533535, 2018.

[23] M. Hempel, N. Rivera Brugués, J. Wagenstaller et al., "Microdeletion syndrome 16p11.2-p12.2: clinical and molecular characterization," American Journal of Medical Genetics Part A, vol. 149A, no. 10, pp. 2106-2112, 2009.

[24] E. K. Bijlsma, A. C. Gijsbers, J. H. Schuurs-hoeijmakers et al., "Extending the phenotype of recurrent rearrangements of 16p11.2: deletions in mentally retarded patients without autism and in normal individuals," European Journal of Medical Genetics, vol. 52, no. 2-3, pp. 77-87, 2009.

[25] J. J. Leblanc and C. A. Nelson, "Deletion and duplication of $16 \mathrm{p} 11.2$ are associated with opposing effects on visual evoked potential amplitude," Molecular Autism, vol. 7, p. 30, 2016.

[26] M. Verbitsky, R. Westland, A. Perez et al., "The copy number variation landscape of congenital anomalies of the kidney and urinary tract," Nature Genetics, vol. 51, no. 51, pp. 117-127, 2019. 